J. Dairy Sci. 95:6831-6842

http://dx.doi.org/10.3168/jds.2012-5677

(C) American Dairy Science Association ${ }^{\circledR}, 2012$.

\title{
ADSA Foundation Scholar Award: Trends in culture-independent methods for assessing dairy food quality and safety: Emerging metagenomic tools
}

\author{
Marie Yeung ${ }^{1,2}$ \\ California Polytechnic State University, San Luis Obispo 93407
}

\begin{abstract}
Enhancing the quality and safety of dairy food is critical to maintaining the competitiveness of dairy products in the food and beverage market and in reinforcing consumer confidence in the dairy industry. Raw milk quality has a significant effect on finished product quality. Several microbial groups found in raw milk have been shown to adversely affect the shelf life of pasteurized milk. Current microbiological criteria used to define milk quality are based primarily on culturedependent methods, some of which are perceived to lack the desired sensitivity and specificity. To supplement traditional methods, culture-independent methods are increasingly being used to identify specific species or microbial groups, and to detect indicator genes or proteins in raw milk or dairy products. Some molecular subtyping techniques have been developed to track the transmission of microbes in dairy environments. The burgeoning "-omics" technologies offer new and exciting opportunities to enhance our understanding of food quality and safety in relation to microbes. Metagenomics has the potential to characterize microbial diversity, detect nonculturable microbes, and identify unique sequences or other factors associated with dairy product quality and safety. In this review, fluid milk will be used as the primary example to examine the adequacy and validity of conventional methods, the current trend of culture-independent methods, and the potential applications of metagenomics in dairy food research.
\end{abstract}

Key words: metagenomics, dairy food quality, culture-independent method

\section{INTRODUCTION}

Consumers have many choices in today's food and beverage market. To remain competitive, a dairy food must achieve excellent quality in terms of nutritional

Received May 1, 2012.

Accepted August 19, 2012.

${ }^{1}$ Corresponding author: pmyeung@calpoly.edu

${ }^{2}$ Marie Yeung was the winner of the 2011 ADSA Foundation Scholar Award in Dairy Foods presented at the ADSA Awards Program in New Orleans, Louisiana, on July 12, 2011. values and sensory attributes. To some consumers, good quality may be equivalent to the "wholesomeness" of the product. The scientific criteria used to define quality standards are product-specific, but in general, they can be categorized into physical (e.g., texture), chemical (e.g., milkfat composition), and biological (e.g., presence of certain bacteria). As consumers become more aware of environmental issues, demand will drive the development of products made in an environmentally friendly or a sustainable manner. Under the "wholesomeness" concept, the term "quality" may also encompass "safety" of the product. Food safety is undoubtedly an important factor in positioning dairy products as healthy and wholesome foods. All stakeholders, including producers, processers, retailers, and consumers, would agree that dairy food should not contain harmful substances at a level deemed capable of causing adverse health effects.

To ensure that dairy products meet consumers' expectations, many scientific methods have been developed to correlate specific assay endpoints to dairy food quality and safety. This paper will review some conventional methods, with a specific focus on the microbiological aspect, for assessing dairy food quality and safety. With the burgeoning field of "-omics," the adequacy and validity of current methods will be evaluated and compared with emerging and more contemporary approaches. Fluid milk will be used as the primary example to illustrate the current trend and potential applications of metagenomics.

\section{BIOLOGICAL FACTORS INFLUENCING THE SHELF LIFE OF FLUID MILK}

According to Barbano et al. (2006), fluid milk processors would like to achieve a 60- to 90-d shelf life at $6^{\circ} \mathrm{C}$. An extended shelf life would allow for more efficient marketing and distribution. However, this is a formidable challenge considering that the typical shelf life of HTST-pasteurized milk is 14 to $16 \mathrm{~d}$ (Boor, 2001; Elwell and Barbano, 2006). Because the quality of finished dairy products can be influenced by the raw materials, improving raw milk quality is among the strategies to extend shelf life. To this end, previous 
studies were conducted to determine the biological factors in raw milk that may limit the shelf life of HTSTpasteurized milk (Fromm and Boor, 2004; Barbano et al., 2006). As described below, the refrigerated shelf life of pasteurized milk is thought to be limited by the presence of certain microbes and somatic cell-derived heat-resistant enzymes in raw milk.

Treatments other than HTST can be implemented to reduce the levels of microbes and their derivatives, thereby increasing shelf life. Although higher heat treatment (i.e., ultrapasteurization) of raw milk leads to a longer shelf life, the process inevitably alters milk chemistry, resulting in off-flavors. In fact, Chapman and Boor (2001) found that ultrapasteurized milk was less acceptable to consumers. Microfiltration is an emerging technique that shows promise in improving shelf life without comprising flavor quality (Elwell and Barbano, 2006; Tomasula et al., 2011). However, this technique is cost prohibitive to many dairies. Therefore, to achieve the goal of extending shelf life without compromising the sensory quality, preventing microbes from entering into raw milk and reducing their growth rates is a crucial step. Keeping raw milk sterile is impossible given the ubiquity of microbes in the environment. Nevertheless, strategies such as sanitation and keeping milk at low temperatures have been routinely implemented to reduce microbial load. More effective strategies to improve milk quality will be developed as our understanding of the microbial ecology in raw milk is enhanced.

Raw milk is essentially free of microbes when freshly produced by dairy cows. Microbes ubiquitous in the dairy environment make their way into raw milk when it flows from the cow's udder, through the milking equipment and pipes, and to the storage tanks. Not surprisingly, many microbes originating from the soil in the dairy farms can be subsequently found on the cow udder and therefore in the milk. Based on previous studies using conventional methods, several key microbial groups have crucial effects on raw milk quality. Fromm and Boor (2004) showed that milk samples containing sufficient numbers of endospore-formers or sporeformers led to reduced shelf life of HTST-pasteurized milk. Huck et al. (2007) further found that 2 genera of psychrotolerant endospore-formers, Bacillus and Paenibacillus, were the predominant cause of microbial spoilage of HTST-pasteurized milk samples from New York State when their refrigerated shelf life exceeded $17 \mathrm{~d}$. Molecular fingerprinting of the isolates suggested that some subtypes found in the finished products were identical to those found in the raw milk, indicating that these microbes originated from raw milk (Huck et al., 2007). Geobacillus, Anoxybacillus, and Clostridium are also common endospore-forming genera found in dairy products (Marth and Steele, 2001; Fromm and Boor,
2004; Burgess et al., 2010; De Jonghe et al., 2010). Because endospores are prevalent in soil and are not removed or killed by many processing procedures, it would be useful for milk producers to determine the levels of viable endospores and endospore-formers in raw milk. In addition, other unidentified microbes capable of surviving pasteurization are of interest to dairy producers.

Rapid cooling and refrigerated storage (at $\leq 7^{\circ} \mathrm{C}$ ) of raw milk reduces the growth rate of many mesophilic and thermophilic microbes while selectively favoring the growth of psychrophiles and psychrotrophs. The presence of these microbes is potentially a major cause of milk spoilage. Pseudomonas spp. have long been regarded as spoilage bacteria because of their ability to multiply in dairy products kept at low temperature (White et al., 1978; Ternström et al., 1993; De Jonghe et al., 2011). Many species in this genus also exhibit proteolytic and lipolytic activities that may eventually yield organoleptic defects and thus unacceptable finished products (Malik and Swanson, 1975; Arslan et al., 2011).

Effective pasteurization kills most microbes. However, some microbial metabolites are heat resistant and therefore remain functional in pasteurized milk. For instance, Pseudomonas spp. produce heat-stable proteases and lipases that could contribute to flavor defects in HTST or ultrapasteurized milk (Shelley et al., 1986; Dogan and Boor, 2003; Ercolini et al., 2009; Marchand et al., 2009). However, it is a common belief that such flavor defects are noticeable only when these proteases and lipases are abundant. This implies that high microbial cell numbers must be present in raw milk to produce sufficient amounts of these heatstable enzymes. Enzymatic activities are thought to be negligible in raw milk that conforms to the US Grade A Pasteurized Milk Ordinance (PMO; FDA, 2012), assuming that postpasteurization contamination does not occur. The Grade A PMO was developed by US Public Health Service/Food and Drug Administration, with input from milk regulatory and rating agencies, the dairy industry, education and research institutions, and the public. The standards set forth by the Grade A PMO are recommended for legal adoption by states, counties, and municipalities to encourage a higher level of excellence of milk sanitation practice. Grade A raw milk from an individual milk producer must carry $<100,000 \mathrm{cfu} / \mathrm{mL}$ of total aerobic bacteria. Quality defects attributed to heat-stable enzymes may become apparent when the bacterial count in raw milk greatly exceeds this standard.

Inevitably, raw milk harbors some level of somatic cells (white blood cells and epithelial cells) during in vivo production and milking. Milk SCC increases when 
cow udders have inflammation due to, for example, bacterial infections. The inflammatory reaction leads to an influx of polymorphonuclear neutrophils, other leukocytes, and phagocytes; some of them enter into the lumen of the alveolus and thus increase milk SCC. Sufficient levels of hydrolytic enzymes derived from somatic cells adversely affect milk quality (Nielsen, 2002). In particular, the heat-stable enzymes plasmin and lipoprotein lipase contribute to increased proteolytic and lipolytic activities, thereby decreasing shelf life and the sensory quality of pasteurized milk. Many mastitis-associated bacteria (e.g., Staphylococcus aureus, Streptococcus uberis, Corynebacterium bovis, Escherichia coli, Enterococcus spp., and Arcanobacterium pyogenes) also indirectly affect dairy product quality by metabolizing substrates in milk that result in altered milk composition (Pitkälä et al., 2004; Park et al., 2007; Taponen et al., 2009).

\section{STANDARD AND CONVENTIONAL METHODS FOR ASSESSING FLUID MILK QUALITY}

Mastitis sometimes presents subclinically but can be detected by high milk SCC. Milk SCC are routinely detected by microscopy (i.e., direct microscopic count) after the samples are treated with the Levowitz-Weber modification of the Newman-Lampert stain (Wehr and Frank, 2004). The Grade A PMO specifies that raw milk must carry $<750,000$ somatic cells $/ \mathrm{mL}$. Presumably, raw milk with this level of SCC does not contain large amounts of somatic cell-derived hydrolytic enzymes. As a result, enzymatic activities would be negligible. Nevertheless, to accurately measure the effects of heat-resistant enzymes on milk quality, a more direct measurement of the enzyme quantities produced by microbes or somatic cells, or of enzyme activity, should be developed to complement cell count methods.

Because raw milk quality is known to be affected by the presence of bacteria or their metabolites, as mentioned before, the PMO stipulates that the total bacteria count for Grade A milk from individual farms must be $<100,000 \mathrm{cfu} / \mathrm{mL}$ before pasteurization. The microbiological criterion for commingled milk from several farms is $<300,000 \mathrm{cfu} / \mathrm{mL}$. A total bacteria count of milk samples is determined by the standard plate count (SPC) method, also known as the aerobic plate count method (Wehr and Frank, 2004). This method enumerates culturable mesophilic heterotrophs on standard methods agar. The rationale for allowing this relatively high threshold $(\mathrm{cfu} / \mathrm{mL})$ is that the majority of microbes should be destroyed by pasteurization. Pasteurized milk, on the other hand, is required to have $<20,000 \mathrm{cfu} / \mathrm{mL}$. A potential limitation of the above criteria is that the diversity of microbes is disregarded, even though some groups apparently have a greater adverse effect on milk quality.

Although the presence of endospores in raw milk likely affects the quality of finished products, milk is not routinely tested for endospores or endospore-formers directly. A traditional method, laboratory pasteurization count (LPC), is sometimes used to predict the impact of thermoduric microbes in raw milk on the shelf life of pasteurized milk. In this method, raw milk is heated to a temperature-time combination of $62.8^{\circ} \mathrm{C}$ for 30 min followed by SPC. Therefore, the goal of this test is to determine the number of thermoduric microbes, which are likely endospore-formers, remaining in milk after heat treatment. A high LPC suggests unhygienic production practices, poor raw milk quality, or both. However, the temperature-time combination of the heat treatment differs from the typical HTST process that uses $\geq 71^{\circ} \mathrm{C}$ for $15 \mathrm{~s}$. In addition, the turbulence that occurs during HTST processing cannot be easily simulated by the LPC method. Thus, LPC results cannot be used reliably to predict how the thermoduric microbes present in raw milk respond to the HTST process.

Psychrophilic/psychrotrophic count (PC) and preliminary incubation count (PIC) are conventional methods used to evaluate the presence of spoilage microbes favoring or enduring rapid cooling and cold conditions. These tests require a preincubation of raw milk at $7^{\circ} \mathrm{C}$ for $10 \mathrm{~d}$ and $12.8^{\circ} \mathrm{C}$ for $18 \mathrm{~h}$, respectively, before conducting SPC. The extended incubation period required for the $\mathrm{PC}$ method hinders the provision of timely results and therefore it has generally been abandoned (K. Boor, Cornell University, Ithaca, NY, personal communication). The PIC was developed based on the assumption that certain microbes associated with inadequate hygiene practices, but not with cow microflora, could grow to significant levels under incubation conditions. As with PC, a high PIC is thought to be indicative of poor-quality raw milk likely to yield a reduced shelf life for pasteurized milk. However, scientific evidence gathered by the Cornell University Milk Quality Improvement Program (Murphy, 2010) did not support this correlation. Specifically, the report stated that the predominant bacteria responsible for high PIC are gram-negative bacteria that generally do not survive pasteurization. Unless raw milk is grossly contaminated initially, yielding a bacterial count that exceeds the regulatory limit, the presence of these gram-negative bacteria in raw milk should not influence pasteurized milk quality before the expiration date. Although it is questionable whether PIC serves as an indicator of product quality, it is not 
uncommon for the industry to use this method, perhaps because of an increasing desire for additional tests to gauge raw milk quality.

\section{THE NEED FOR CONTEMPORARY CULTURE- INDEPENDENT METHODS}

\section{Nonculturable Microbes}

When raw milk meets Grade A standards, conventional culture-dependent methods for measuring the presence of contaminating microbes are found to lack predictive power on the shelf life of commercially pasteurized fluid milk (Martin et al., 2011). Other diagnostic methods, independent of culturing, are likely necessary to complement or replace some current methods. Because many traditional methods rely on the capabilities of certain microbial groups to multiply under laboratory conditions, they may hinder the full characterization of the microbiological quality of dairy products because many microbes in the environment are nonculturable (Bakken, 1997; McDougald et al., 1998). The effects of these nonculturable microbes on dairy quality and safety have not been evaluated.

\section{Ropy Milk}

The emerging issue of "ropy milk," which is characterized by higher viscosity and a slimy thread-like appearance, revived some old testing methods to detect milk with the tendency to "rope" before the end of shelf life. Several bacteria genera are associated with the ropiness phenotype, but the exact cause is not well understood (Morton and Barrett, 1982; Cheung and Westhoff, 1983). Ropiness is believed to be the result of biopolymer or exopolysaccharide production by certain species in the genera Klebsiella and Pseudomonas, and possibly by endospore-formers and other bacteria at lower abundance (Cheung and Westhoff, 1983; Dlamini and Peiris, 1997; R. Jimenez-Flores, California Polytechnic State University, San Luis Obispo, unpublished data). Genes encoding for secretory polysaccharides are known to be present on mobile genetic elements, which are DNA sequences capable of moving within the chromosome or between bacterial cells. Therefore, multiple different microbes may express similar genes resulting in exopolysaccharide production (Pickard et al., 2003; Eng et al., 2011).

Because no single culprit has been identified as the cause of ropiness, numerous processing facilities examine milk for this defect by first incubating the milk at a certain temperature and then carefully pouring the milk, or by inserting and then withdrawing a solid cylindrical rod while observing for sticky or viscous flow.
These test procedures lack uniformity and results are often inconsistent. Nevertheless, it is not uncommon for milk to be rejected because of a positive result in this single test (K. Boor, Cornell University, Ithaca, NY, personal communication). The ropy milk issue and the uncertain validity of PIC method are among the reasons underscoring the critical need for more reliable, scientifically sound methods to gauge milk quality.

\section{Mobile Genetic Elements}

Mobile genetic elements are also responsible for pathogenesis in some foodborne pathogens such as Shiga toxin-producing Escherichia coli and Salmonella enterica serovar Typhimurium (Bolton, 2011; Lopez et al., 2012). Horizontal gene transfer (HGT) of virulence genes may allow previously nonpathogenic microbes to become pathogenic to humans. The acquisition of virulence genes by thermoduric microbes capable of surviving pasteurization represents a potential food safety problem. Conventional methods aimed at detecting specific pathogens may overlook the potential impact of HGT. Hence, direct detection of virulence genes or proteins may be necessary to supplement current assessment methods. Cobbold et al. (2008) demonstrated that conventional methods aimed at detecting E. coli O157:H7 failed to detect other toxigenic E. coli serotypes in raw milk. These results highlight the need for an alternative or a supplementary approach, such as the detection of stx1 and stx2 genes encoding the Shiga toxin.

The number of foodborne illnesses caused by antibiotic-resistant pathogens has increased in recent years. Many researchers are investigating the cause, transmission, and distribution of these microbes in dairy environments (Alcaine et al., 2005; Hoelzer et al., 2010; Haran et al., 2012). Transfer of antibiotic resistance genes among different microbes by means of HGT is not an uncommon event (Alcaine et al., 2005; Hawkey, 2008). Raw milk and dairy products are potential arenas where gene transfer could take place because milk contains multiple, diverse microbes. In fact, antibiotic-resistant microbes, or genes contributing to the antibiotic resistance phenotype, have been detected in several different dairy products. For example, tetracycline-resistant Campylobacter spp. were found in US milk samples (Halbert et al., 2006); clindamycin- and erythromycin-resistant Lactococcus spp. were found in Swiss milk samples (Walther et al., 2008); cephalosporin- and aztreonam-resistant Klebsiella pneumoniae were found in Japanese milk samples (Hammad et al., 2008); and erythromycin-resistance genes were found in Mozzarella cheese samples in Italy (Devirgiliis et al., 2008). Noncommercial starter cultures and other com- 
mensal bacteria may serve as reservoirs of antibiotic resistance genes (Straley et al., 2006). The co-localization of these bacteria and pathogens in dairy environments, including dairy products, facilitates HGT between these groups. A high-throughput method capable of determining the occurrence and tracking the transmission of multiple antibiotic resistance genes from raw milk to finished product will help in the development and evaluation of control strategies.

\section{THE ERA OF -OMES AND -OMICS}

In the 1990s, the scientific world entered a new era of "-omes" when large-scale sequencing projects on microbes were launched. In 1995, the first complete genome of a free-living organism, the bacterium Haemophilus influenzae, was obtained (Fleischmann et al., 1995). A draft sequence of the human genome was released in 2001 (Lander et al., 2001; Venter et al., 2001). The study of genomes (genomics) and the associated emerging technologies address a wide array of scientific questions. Following the determination of DNA sequence and genome structure, the next logical step is an informative analysis. Functional genomics has therefore evolved to study the dynamic aspects of genomes such as gene transcription, translation, and protein-protein interaction. Extensions of genome and genomics are transcriptomes and transcriptomics, respectively, which focus on the expression of whole genomes; that is, observing the RNA.

The "-omes" and "-omics" suffixes have extended to various disciplines involving large-scale data set and high-throughput analysis. Nutrigenomics, pharmacogenomics, ecogenomics, and toxicogenomics entail studies on genomic sequence variability due to differential responses to food, drug, environment, and toxic substances, respectively. The entire sets of proteins, glycoproteins, glycan structure, and lipid profile are studied in the fields of proteomics, glycoproteomics, glycomics, and lipidomics, respectively. Tuohy et al. (2009) described the application of 2 omics approaches: metabolomics, the study of metabolic kinetic and flux of metabolites, and metagenomics, the study of multiple genomes, to determine the association between changes in metabolite profiles within human biofluids and microbiota composition. The combination of the approaches described above is called transgenomics.

Omics technologies are increasingly applied to study the biology, nutrition, and management of ruminant animals (Dawson, 2006; Hocquette et al., 2009; Bauman et al., 2011; Bendixen et al., 2011; Santos et al., 2011). To facilitate understanding of the biological processes underlying mammalian milk genomics, the International Milk Genomics Consortium was established in 2004 (http://milkgenomics.org/). In terms of food products, omics technologies have been applied to various food commodities to carry out food component analysis, authenticity assessment, and contaminant analysis, and to characterize the dynamics of microbial communities (Casado et al., 2009; Iijima and Aoki, 2009; Chassy, 2010; Giribaldi and Giuffrida, 2010; Rohrmann et al., 2011; Weckx et al., 2011). As discussed below, the effects of food on the gut microbiome, which is the collection of genes and genomes of the microbiota, have also been recently investigated. Although the omics approach may not provide the ultimate answer to all problems, it certainly offers new opportunities to address questions related to dairy food quality and safety, especially because some traditional and conventional methods are perceived to lack the desired sensitivity and specificity. In fact, the term "foodomics" was recently coined to describe a discipline that studies food and nutrition domains through the application of omics technologies, including nutrigenomics and nutrigenetics (Cifuentes, 2009). Foodomics also includes the study of food products ranging from compound profiling, authenticity, and effects on human health, to biomarker detection for food quality or safety (Herrero et al., 2012).

\section{EMERGING METAGENOMIC TOOLS}

Recent advances in sequencing technology enable large-scale data acquisition in a more rapid and affordable manner. This "next-generation sequencing" has an unprecedented ability to process millions of DNA fragments and to generate sequence reads (i.e., short, sequenced fragments) within a short time. Many wholegenome sequence projects on microbes associated with dairy food production and functionality are complete or underway (http://cmr.jcvi.org/). Some examples are Lactobacillus acidophilus NCFM, Lactobacillus casei ATCC 334, Lactobacillus delbrueckii ssp. bulgaricus ATCC 11842 and ATCC BAA-365, and Streptococcus thermophilus CNRZ1066, LMD-9, and LMG 18311.

Metagenomics builds on the concept of genomics, in which genomes from multiple, diverse types of organisms inhabiting a common environment are acquired. The first metagenomics project was reported in 2002 on the marine viral community in San Diego, California (Breitbart et al., 2002). Since then, the number of metagenomic projects or studies has increased substantially. The Genomes OnLine Database contains more than 340 studies associated with 1,927 samples (Pagani et al., 2012). These samples range from drinking water, Sargasso Sea water, farm soil, human gut, termite hindgut, subsurface oil reservoir, and a hypersaline mat (Schmeisser et al., 2003; Venter et al., 2004; Tringe et al., 2005; Gill et al., 2006; Warnecke et al., 2007; Kunin 
et al., 2008b; Kotlar et al., 2011). A generic procedure for metagenomics is outlined as follows.

\section{Sample Preparation}

Sample storage and subsequent DNA extraction method must yield nonbiased nucleic acid materials to prepare templates for the next step-sequencing. Bahl et al. (2012) showed that fecal samples frozen for an extended period yielded different DNA representations than the nonfrozen counterparts. This finding suggests that samples must be relatively fresh before DNA extraction. The first step of DNA extraction is cell lysis, which may be achieved by mechanical (e.g., bead beating), chemical (e.g., SDS), or enzymatic (e.g., lysozyme) means (Cremonesi et al., 2006; Hwang et al., 2012). Isolation and purification of DNA can be achieved by a wide array of techniques including phenol/chloroform-, ethanol-, or resin-based methods. Many commercial kits are available for extracting DNA from various biological samples, several of which also contain reagents to remove enzymatic inhibitors that may interfere with subsequent processing. Because dairy products may contain endospores that are difficult to lyse, and may contain components that could interfere with DNA extraction and downstream processing, different DNA extraction methods must be compared empirically to identify the most effective one before sequencing.

\section{Sequencing}

Different high-throughput sequencing (HTS) platforms have been used by metagenomic projects. Common platforms include Roche 454 (454 Life Sciences, a Roche Company, Branford, CT), Solexa (Illumina Inc., San Diego, CA), SOLid (Life Technologies Corp., Carlsbad, CA), HeliScope (Helico BioSciences Corp., Cambridge, MAand Polonator (Dover Systems, Salem, NH; Metzker, 2010). The Ion Torrent system from Life Technologies Corp., based on semiconductor technology, has also recently emerged. In general, these platforms can be distinguished from one another by the library or template preparation methods, sequencing chemistry, and read lengths. The cost for sequencing $1 \mathrm{Mbp}$ is estimated to range from $\sim \$ 1$ (HeliScope) to $\$ 60$ (Roche 454; Shendure and Ji, 2008). These estimates exclude the cost of the instrument and are likely outdated in this rapidly changing field. However, they illustrate the increasing affordability to conduct metagenomic studies. High-throughput sequencing produces raw sequence data in a rapid manner. For example, it takes only a few hours to sequence the whole genome of a bacterium with a genome size of 4 to $6 \mathrm{Mbp}$ about 10 times (i.e., $10 \times$ coverage). Including the time required to prepare the templates, metagenomes can easily be obtained in a few weeks.

\section{Assembly}

Following sequencing, reads must be assembled to establish the order of the fragments. Compared with Sanger sequencing, many HTS platforms yield short read lengths, ranging from 10 to $330 \mathrm{bp}$ (Shendure and Ji, 2008; Metzker, 2010). The metagenomic data set often contains nonuniform read depths due to nonuniform distribution of species abundance, and hence, an increased likelihood of co-assembly of reads originating from different species; that is, chimera contigs (Kunin et al., 2008a). Therefore, programs designed to assemble genomes would not be suitable for metagenomes. Several programs based on the comparative assembly approach (i.e., reference-based assembly) or de novo assembly were developed to assemble metagenomes specifically (Thomas et al., 2012). Although the algorithms are faster, reference-based assembly programs are perceived to have more potential bias because they cannot accurately assemble novel genomic sequences (Lai et al., 2012). On the other hand, de novo assembly programs typically require greater computational resources.

Given the short read length, metagenomic data usually cannot be assembled to determine whole prokaryotic chromosome organization, unless the sample is significantly dominated by one species. Nevertheless, the data can reveal single nucleotide polymorphisms, short functional signatures, single domain genes, and possibly short operons and multidomain genes (Wooley et al., 2010). In the future, when a single chromosome can be sequenced in a single pass with few or no fragments, assembly algorithms may become obsolete.

\section{Gene Calling}

After assembly, gene calling (i.e., gene prediction) can be done by "evidence-based" or "ab initio" approaches (Kunin et al., 2008a). The purpose of using gene-finding algorithms is to find open reading frames (ORF) constituting a gene. The former approach is common for genes with sequences homologous to those already existing in databases. The Basic Local Alignment Search Tool (BLAST; http://blast.ncbi.nlm.nih.gov/Blast. cgi) is often used to find gene family members within a metagenome. However, because this approach relies on existing information in databases, BLAST cannot be used to find new genes. In contrast, the ab initio gene prediction tools are mostly based on statistical pattern recognition methods to identify putative genes. Thus, genes are predicted according to the intrinsic property 
of the sequence such as codon usage, without reference to existing databases. Markov models or hidden Markov models are common statistical tools used for modeling. For example, FragGeneScan combines sequencing error models and codon usages in a hidden Markov model (Rho et al., 2010). Other software specifically designed for analyzing metagenomes include MetaGene, which obtains training sets by using 2 generic models (archaea and bacteria) (Noguchi et al., 2006). Another approach, used to analyze the global ocean metagenome, is based on an incremental clustering method and begins with ORF identification of consecutive translatable regions coding for at least 60 amino acids (Yooseph et al., 2007, 2008). With new algorithms being developed rapidly, it is likely that the use of multiple different approaches will achieve better sensitivity and specificity in gene calling.

\section{Functional Annotation}

Following the identification of putative ORF, the next step is to determine the functions of these ORF, in a process called functional annotation. Putative full or partial ORF can be searched for patterns that are widespread and have known biological significance (i.e., motifs) or for other sequence signatures correlated with certain functionality. Using BLAST with unassembled, relatively long single reads could also yield useful information. The classic example is "BLASTing" $16 \mathrm{~S} / 18 \mathrm{~S}$ ribosomal (r)DNA to determine species distribution. Because predicted genes (and hence, proteins) in a metagenome are often fragmented, additional approaches may be required for more accurate annotation. Dalevi et al. (2008) suggested that the "proxygene" method is more accurate than direct assignment to protein families using reverse position-specific BLAST on metagenomes generated by the Roche 454 sequencer. Proxygene is defined as "a full-length protein identified by a BLASTx search of read sequences against a protein sequence database and then is used as a representative of a read or group of reads." The effectiveness of such evidence-based clustering methods for taxonomic analysis of metagenome data is also supported by Folino et al. (2009). Once functional annotation is complete, more in-depth data analyses can be performed to answer specific research questions, such as the relationships between metagenome and metadata (e.g., other data about the samples such as habitat and physical parameters).

It is evident that metagenomics can generate massive amount of data derived from complex communities. After a long and sometimes daunting process to analyze and filter the data, useful information can be discovered, and such discoveries may lead to new re- search directions. The following examples on non-dairyrelated research illustrate how exciting information can be gleaned from metagenomes. Turnbaugh et al. (2006) demonstrated that obese animal subjects harbored a relatively higher abundance of Firmicutes compared with Bacteroidetes. Further studies suggested that gut microflora facilitate fermentation of indigestible carbohydrates to short-chain fatty acids and the ratio between these phyla may drive a change in fermentation patterns (Arora and Sharma, 2011). The absorption of the fermentation products, coupled with other factors such as differential innate immune response to Firmicutes, may influence weight gain (Turnbaugh et al., 2006; Kallus and Brandt, 2012). In another study, metagenomics was used not only to detect the presence of a nonculturable microbe, but also to determine its potential function (Donia et al., 2011). These authors suggested that Prochloron didemni, a nonculturable microbial symbiont with a primitive marine animal, profoundly influences the lipid composition of the animal host by synthesizing and supplying sterols and an unusual lipid. The unusual lipid was shown to have biofuel potential.

\section{POTENTIAL APPLICATIONS OF METAGENOMICS IN DAIRY FOOD QUALITY AND SAFETY}

In the dairy food quality and safety arena, metagenomic approaches will also allow the discovery of new information and help create new research opportunities. With the potential to characterize microbial diversity, determine the presence of target genes (e.g., virulence and antibiotic resistance genes), and detect and identify microbes simultaneously, metagenomics may soon replace certain molecular strategies, such as PCR and microarray using species-specific primers or probes, designed to detect microbial components of dairy food. Metagenomics can also be used to study the roles of nonculturable microbes and quorum sensing in product quality and safety. More examples are shown below to illustrate other potential applications of metagenomics.

\section{Development of Diagnostic Tests}

Currently, no strong consensus exists on what combination of conventional testing methods would produce results with the most relevance to assessing and predicting the shelf life of HTST-pasteurized milk. Contemporary approaches, and hence the information generated, may be necessary to unify existing methods and identify new criteria for the production of highquality dairy products. To this end, metagenomics can be used to compare dairy products of varying qualities as defined by conventional methods or the shelf life of 
finished products. Our research group has studied the associations between microbes and fluid milk quality using a comparative approach. We obtained the terminal restriction fragment length polymorphism (T-RFLP) patterns from high- and low-quality milk samples, as defined by conventional culture-dependent tests. These patterns were then compared to identify putative factors affecting raw milk quality. Our data corroborated the negative correlation between the presence of Pseudomonas spp. and raw milk quality. In addition, we identified some T-RFLP peaks corresponding to nonculturable bacteria that were of relatively high abundance in lower quality milk (H. Guo, Shanghai Jiao Tong University, China, and California Polytechnic State University, San Luis Obispo; M. Yeung, C. Kitts, and R. Jimenez-Flores, all of California Polytechnic State University, unpublished data). It is foreseeable that comparative studies based on metagenomics could provide more comprehensive profiles of these samples. One possible outcome is the identification of "sequence signatures" associated with quality and safety of dairy products. Conventional molecular techniques, such as oligoarrays or sensors, could then be developed to detect these sequence signatures on farms or at processing plants to facilitate cost-effective and faster quality control testing.

\section{Microbial Ecology of Dairy Food}

Unequivocally, microbes play a crucial role in dairy products, especially fermented dairy products. To determine the community structure in these products at the species level or above, conventional approaches rely mostly on culturing, PCR, T-RFLP, and 16S rDNA sequencing (Delbès et al., 2007; Cocolin et al., 2009; Carraro et al., 2011; Liu et al., 2012). By obtaining the microbiome of milk samples collected from 3 groups of cattle with subclinical mastitis, Bhatt et al. (2012) showed that the metagenomics approach yields more information than most conventional methods. In that study, the metagenomes were mined to determine the relative abundance of various microbial species associated with mastitis, as well as the presence of bacteriophages and sequences associated with virulence and antibiotic resistance. By finding the microbes associated with mastitis in these cattle, and the possible interactions among them, the authors argued that better prevention and treatment strategies could be formulated.

A few studies also applied metagenomics on fermented nondairy food (Jung et al., 2011; Weckx et al., 2011). The following example illustrates a potential application of metagenomics to the dairy sector. Kimchi is a spontaneously fermented vegetable product that naturally harbors many microbes. The metagenome revealed that Leuconostoc mesenteroides, Lactobacillus sakei, and Weissella spp. are the major bacteria in this product (Jung et al., 2011). Some of these microbes are known to carry out heterolactic fermentation. The metagenome confirms the presence of protein-encoding sequences that match heterolactic pathways. Another interesting finding from this metagenome is the presence of a large number of phage DNA elements, indicating that the bacteria are often subjected to bacteriophage infection. These elements, known as the clustered regularly interspaced short palindromic repeats (commonly referred to as CRISPR), confer resistance to the host bacteria against subsequent infection. The CRISPR were found in certain strains of Lactobacillus sanfranciscensis isolated from sourdough, and the presence of these elements appears to confer to these strains the ability to impede gene intrusion (Vogel et al., 2011). In another study, the phage resistance mechanism of bacteriophage-insensitive mutants of Streptococcus thermophilus was investigated by using a genomic approach (Mills et al., 2010). The number and location of phage-derived genetic fragments, called spacers, within the CRISPR region appear to be responsible for the phage resistance phenotype. The above findings suggest that naturally phage-resistant bacteria are widespread and might be exploited to protect fermented dairy foods from phage attack.

\section{Fingerprinting and Traceability}

The ability to trace the sources and identify transmission routes of both spoilage and pathogenic microbes is necessary to ensure food quality and safety. Currently, to differentiate among bacterial strains, multilocus sequencing typing, pulsed-field gel electrophoresis, ribotyping, single-strand conformation polymorphism, and PCR-based subtyping methods are commonly used (Giraffa et al., 2004; Yeung et al., 2004; Delbès et al., 2007; Hoelzer et al., 2010). These methods generate sequences or banding patterns for each microbial subtype, known as molecular fingerprinting. Metagenomics is yet to be developed as a subtyping tool; nevertheless, as discussed below, empirical evidence supports the potential for metagenomics as a microbial tracking tool.

Theoretically, metagenomic approaches have the ability to establish a bona fide molecular fingerprint of samples, potentially allowing traceability along the food chain. Performance of metagenomics as a forensic tool was tested by Fierer et al. (2010). These authors first demonstrated that skin-associated bacterial communities on an individual's skin as well as inanimate objects touched by the individual could be identified using metagenomics. With this knowledge, metage- 
nomic data could be used to trace the individual who had touched the objects with a high degree of certainty. In the future, metagenomics and other omics technologies may be useful in determining the identity and authenticity of specialty, artisan, and farmstead dairy fermented foods based on their unique molecular fingerprints.

\section{Dairy Food and Human Microbiome}

From bone health to curbing obesity, dairy products have long been regarded as health-promoting foods (Caroli et al., 2011; Dougkas et al., 2011). Metagenomics is indispensable in our quest to understand the health benefits of dairy products in relation to human microbiome. Increasing evidence suggests that the human gut microbiome is influential in altering energy balance, thereby contributing to an obese phenotype (Arora and Sharma, 2011; Kallus and Brandt, 2012). Because the intestinal flora influence the metabolism of the host, manipulating the gut microbiome may be a potential therapeutic treatment to address certain diseases such as obesity, cancer, and type II diabetes mellitus (Lampe, 2011). One way to manipulate the gut microbiome is through the consumption of probiotics. According to the United Nations/Food and Agriculture Organization and World Health Organization, probiotics are defined as "live microorganisms which when administered in adequate amounts confer a health benefit on the host" (FAO/WHO, 2002). For many years, dairy products have served as excellent vehicles to deliver probiotics to consumers. More research on these dairy products will confirm or reveal the roles of probiotics in influencing the human gut microbiome. On the other hand, the gut microbiome can also be altered by stimulating the growth of indigenous probiotics residing in the gut (i.e., the consumption of prebiotics). This is exemplified by the growth-stimulating effects of human milk oligosaccharides on Bifidobacterium longum ssp. infantis ATCC 15697 (Sela et al., 2012). Dairy products likely contain many yet-to-be-discovered compounds capable of modulating the gut microbiome.

\section{Limitations of the Metagenomics Approach}

Although the emerging metagenomic tools may provide new information to complement and challenge our concept of dairy food quality and safety, the full potential and widespread adoption of metagenomics in the dairy industry can only materialize when the cost and technical expertise associated with DNA sequencing and data analysis become manageable. Extraction and sequencing steps will likely become fully automated in the near future. Optimizing procedures for routine and systematic data maintenance and analyses, however, will take time. Despite an increasingly high-throughput nature, current metagenomic analyses lack the ability to determine the absolute number of genes or organisms in a given sample. In circumstances where relative abundance is insufficient to answer specific questions, conventional methods such as microscopy, spectrophotometry, culturing, or quantitative PCR will still be required. Last but not least, metagenomics is sometimes regarded as a discovery tool to generate hypotheses. Genes or gene components that are identified to be associated with product quality and safety may not be the causative factors. More research must therefore be conducted after the discovery phase to determine the precise relationship between them.

\section{CONCLUSIONS}

Culture-independent methods are becoming increasingly important in assessing the quality and safety of dairy products. Among these methods are the burgeoning omics technologies. A metagenomic approach offers exciting research opportunities, such as the development of new diagnostic tests, the potential application as fingerprinting tools, and the study of the human gut microbiome. Given its increasingly high-throughput nature, metagenomics may replace certain culture-dependent and molecular methods. Integration of multiple omics approaches will likely be the future to obtain a more comprehensive picture of product quality and safety. Such integration may include a transcriptomicsbased cytosensor assay, which probes toxicity-related gene pathway responses of human cells upon stimulation by food extracts, to assess the safety of dairy products. The recent debate on raw milk consumption in the United States underscores the need for a more comprehensive approach to assess raw milk safety. In the future, omics may be able to offer a solution to satisfy every consumer.

\section{ACKNOWLEDGMENTS}

The author is extremely grateful to Kathryn J. Boor (Cornell University, Ithaca, NY) and to Rafael JimenezFlores and Christopher L Kitts (California Polytechnic State University, San Luis Obispo) for critically reviewing this manuscript. The author is also extremely thankful for the continuous support-professional and personal-generously provided by Kathryn Boor, Raul Cano (California Polytechnic State University, San Luis Obispo), Rafael Jimenez-Flores, Christopher Kitts, Hélène Marquis (Cornell University, Ithaca, NY), Mary Ellen Sanders (Dairy \& Food Culture Technologies, Centennial, CO), Phillip Tong (California Polytechnic 
State University, San Luis Obispo), and Martin Wiedmann (Cornell University, Ithaca, NY). Direct and indirect funding support from Dairy Management Inc. (Rosemont, IL), California Department of Food and Agriculture, and California Polytechnic State University (San Luis Obispo) is also greatly appreciated.

\section{REFERENCES}

Alcaine, S. D., S. S. Sukhnanand, L. D. Warnick, W. L. Su, P. McGann, P. McDonough, and M. Wiedmann. 2005. Ceftiofur-resistant Salmonella strains isolated from dairy farms represent multiple widely distributed subtypes that evolved by independent horizontal gene transfer. Antimicrob. Agents Chemother. 49:4061-4067.

Arora, T., and R. Sharma. 2011. Fermentation potential of the gut microbiome: Implications for energy homeostasis and weight management. Nutr. Rev. 69:99-106.

Arslan, S., A. Eyi, and F. Ozdemir. 2011. Spoilage potentials and antimicrobial resistance of Pseudomonas spp. isolated from cheeses. J. Dairy Sci. 94:5851-5856.

Bahl, M. I., A. Bergstrom, and T. R. Licht. 2012. Freezing fecal samples prior to DNA extraction affects the Firmicutes to Bacteroidetes ratio determined by downstream quantitative PCR analysis. FEMS Microbiol. Lett. 329:193-197.

Bakken, L. R. 1997. Culturable and nonculturable bacteria in soil. Pages 47-61 in Modern Soil Microbiology. J. D. van Elsas, J. T. Trevors, and E. M. H. Wellington, ed. Marcel Dekker, New York, NY.

Barbano, D. M., Y. Ma, and M. V. Santos. 2006. Influence of raw milk quality on fluid milk shelf life. J. Dairy Sci. 89(E. Suppl.):E15E19.

Bauman, D. E., K. J. Harvatine, and A. L. Lock. 2011. Nutrigenomics, rumen-derived bioactive fatty acids, and the regulation of milk fat synthesis. Annu. Rev. Nutr. 31:299-319.

Bendixen, E., M. Danielsen, K. Hollung, E. Gianazza, and I. Miller. 2011. Farm animal proteomics-A review. J. Proteomics 74:282293.

Bhatt, V. D., V. B. Ahir, P. G. Koringa, S. J. Jakhesara, D. N. Rank, D. S. Nauriyal, A. P. Kunjadia, and C. G. Joshi. 2012. Milk microbiome signatures of subclinical mastitis-affected cattle analysed by shotgun sequencing. J. Appl. Microbiol. 112:639-650.

Bolton, D. J. 2011. Verocytotoxigenic (Shiga toxin-producing) Escherichia coli: Virulence factors and pathogenicity in the farm to fork paradigm. Foodborne Pathog. Dis. 8:357-365.

Boor, K. J. 2001. ADSA Foundation Scholar Award: Fluid dairy product quality and safety: Looking to the future. J. Dairy Sci. 84:1-11.

Breitbart, M., P. Salamon, B. Andresen, J. M. Mahaffy, A. M. Segall, D. Mead, F. Azam, and F. Rohwer. 2002. Genomic analysis of uncultured marine viral communities. Proc. Natl. Acad. Sci. USA 99:14250-14255.

Burgess, S. A., D. Lindsay, and S. H. Flint. 2010. Thermophilic bacilli and their importance in dairy processing. Int. J. Food Microbiol. 144:215-225.

Caroli, A., A. Poli, D. Ricotta, G. Banfi, and D. Cocchi. 2011. Invited review: Dairy intake and bone health: A viewpoint from the state of the art. J. Dairy Sci. 94:5249-5262.

Carraro, L., M. Maifreni, I. Bartolomeoli, M. E. Martino, E. Novelli, F. Frigo, M. Marino, and B. Cardazzo. 2011. Comparison of culture-dependent and -independent methods for bacterial community monitoring during Montasio cheese manufacturing. Res. Microbiol. 162:231-239.

Casado, B., M. Affolter, and M. Kussmann. 2009. OMICS-rooted studies of milk proteins, oligosaccharides and lipids. J. Proteomics 73:196-208.

Chapman, K. W., and K. J. Boor. 2001. Acceptance of $2 \%$ ultrapasteurized milk by consumers, 6 to 11 years old. J. Dairy Sci. 84:951-954.
Chassy, B. M. 2010. Can -omics inform a food safety assessment? Regul. Toxicol. Pharmacol. 58:S62-S70.

Cheung, B. A., and D. C. Westhoff. 1983. Isolation and identification of ropy bacteria in raw milk. J. Dairy Sci. 66:1825-1834.

Cifuentes, A. 2009. Food analysis and foodomics foreword. J. Chromatogr. A 1216:7109.

Cobbold, R. N., M. A. Davis, D. H. Rice, M. Szymanski, P. I. Tarr, T. E. Besser, and D. D. Hancock. 2008. Associations between bovine, human, and raw milk, and beef isolates of non-O157 Shiga toxigenic Escherichia coli within a restricted geographic area of the United States. J. Food Prot. 71:1023-1027.

Cocolin, L., D. Nucera, V. Alessandria, K. Rantsiou, P. Dolci, M. A. Grassi, S. Lomonaco, and T. Civera. 2009. Microbial ecology of Gorgonzola rinds and occurrence of different biotypes of Listeria monocytogenes. Int. J. Food Microbiol. 133:200-205.

Cremonesi, P., B. Castiglioni, G. Malferrari, I. Biunno, C. Vimercati, P. Moroni, S. Morandi, and M. Luzzana. 2006. Improved method for rapid DNA extraction of mastitis pathogens directly from milk. J. Dairy Sci. 89:163-169.

Dalevi, D., N. N. Ivanova, K. Mavromatis, S. D. Hooper, E. Szeto, P. Hugenholtz, N. C. Kyrpides, and V. M. Markowitz. 2008. Annotation of metagenome short reads using proxygenes. Bioinformatics 24:i7-i13.

Dawson, K. A. 2006. Nutrigenomics: Feeding the genes for improved fertility. Anim. Reprod. Sci. 96:312-322.

De Jonghe, V., A. Coorevits, J. De Block, E. Van Coillie, K. Grijspeerdt, L. Herman, P. De Vos, and M. Heyndrickx. 2010. Toxinogenic and spoilage potential of aerobic spore-formers isolated from raw milk. Int. J. Food Microbiol. 136:318-325.

De Jonghe, V., A. Coorevits, K. v. Hoorde, W. Messens, A. v. Landschoot, P. d. Vos, and M. Heyndrickx. 2011. Influence of storage conditions on the growth of Pseudomonas species in refrigerated raw milk. Appl. Environ. Microbiol. 77:460-470.

Delbès, C., L. Ali-Mandjee, and M. C. Montel. 2007. Monitoring bacterial communities in raw milk and cheese by culture-dependent and -independent 16S rRNA gene-based analyses. Appl. Environ. Microbiol. 73:1882-1891.

Devirgiliis, C., A. Caravelli, D. Coppola, S. Barile, and G. Perozzi. 2008. Antibiotic resistance and microbial composition along the manufacturing process of Mozzarella di Bufala Campana. Int. J. Food Microbiol. 128:378-384.

Dlamini, A., and P. Peiris. 1997. Biopolymer production by a Klebsiella oxytoca isolate using whey as fermentation substrate. Biotechnol. Lett. 19:127-130.

Dogan, B., and K. J. Boor. 2003. Genetic diversity and spoilage potentials among Pseudomonas spp. isolated from fluid milk products and dairy processing plants. Appl. Environ. Microbiol. 69:130138.

Donia, M. S., W. F. Fricke, F. Partensky, J. Cox, S. I. Elshahawi, J. R. White, A. M. Phillippy, M. C. Schatz, J. Piel, M. G. Haygood, J. Ravel, and E. W. Schmidt. 2011. Complex microbiome underlying secondary and primary metabolism in the tunicate-Prochloron symbiosis. Proc. Natl. Acad. Sci. USA 108:E1423-E1432.

Dougkas, A., C. K. Reynolds, I. D. Givens, P. C. Elwood, and A. M. Minihane. 2011. Associations between dairy consumption and body weight: A review of the evidence and underlying mechanisms. Nutr. Res. Rev. 24:72-95.

Elwell, M. W., and D. M. Barbano. 2006. Use of microfiltration to improve fluid milk quality. J. Dairy Sci. 89(E. Suppl.):E20-E30.

Eng, C., A. Thibessard, M. Danielsen, T. B. Rasmussen, J.-F. Mari, and P. Leblond. 2011. In silico prediction of horizontal gene transfer in Streptococcus thermophilus. Arch. Microbiol. 193:287-297.

Ercolini, D., F. Russo, I. Ferrocino, and F. Villani. 2009. Molecular identification of mesophilic and psychrotrophic bacteria from raw cow's milk. Food Microbiol. 26:228-231.

FAO/WHO. 2002. Guidelines for the Evaluation of Probiotics in Food. Food and Agriculture Organization of the United Nations (FAO), Rome, Italy, and World Health Organization (WHO), Geneva, Switzerland.

FDA (Food and Drug Administration). 2012. National Conference on Interstate Milk Shipments (NCIMS) Model Documents. Accessed 
Sep. 27, 2012. http://www.fda.gov/Food/FoodSafety/ProductSpecificInformation/MilkSafety/NationalConferenceonInterstateMilkShipmentsNCIMSModelDocuments/default.htm.

Fierer, N., C. L. Lauber, N. Zhou, D. McDonald, E. K. Costello, and R. Knight. 2010. Forensic identification using skin bacterial communities. Proc. Natl. Acad. Sci. USA 107:6477-6481.

Fleischmann, R. D., M. D. Adams, O. White, R. A. Clayton, E. F. Kirkness, A. R. Kerlavage, et al. 1995. Whole-genome random sequencing and assembly of Haemophilus influenzae Rd. Science 269:496-512.

Folino, G., F. Gori, M. S. M. Jetten, and E. Marchiori. 2009. Evidencebased clustering of reads and taxonomic analysis of metagenomic data. Pages 102-112 in Pattern Recognition in Bioinformatics, Proceedings. Vol. 5780. V. Kadirkamanathan, G. Sanguinetti, M. Girolami, M. Niranjan, and J. Noirel, ed. Springer-Verlag, Berlin, Germany.

Fromm, H. I., and K. J. Boor. 2004. Characterization of pasteurized fluid milk shelf-life attributes. J. Food Sci. 69:M207-M214.

Gill, S. R., M. Pop, R. T. DeBoy, P. B. Eckburg, P. J. Turnbaugh, B. S. Samuel, J. I. Gordon, D. A. Relman, C. M. Fraser-Liggett, and K. E. Nelson. 2006. Metagenomic analysis of the human distal gut microbiome. Science 312:1355-1359.

Giraffa, G., C. Andrighetto, C. Antonello, M. Gatti, C. Lazzi, G. Marcazzan, A. Lombardi, and E. Neviani. 2004. Genotypic and phenotypic diversity of Lactobacillus delbrueckii subsp lactis strains of dairy origin. Int. J. Food Microbiol. 91:129-139.

Giribaldi, M., and M. G. Giuffrida. 2010. Heard it through the grapevine: Proteomic perspective on grape and wine. J. Proteomics 73:1647-1655.

Halbert, L. W., J. B. Kaneene, J. Linz, L. S. Mansfield, D. Wilson, P. L. Ruegg, L. D. Warnick, S. J. Wells, C. P. Fossler, A. M. Campbell, and A. M. Geiger-Zwald. 2006. Genetic mechanisms contributing to reduced tetracycline susceptibility of Campylobacter isolated from organic and conventional dairy farms in the midwestern and northeastern United States. J. Food Prot. 69:482-488.

Hammad, A. M., A. M. Ahmed, Y. Ishida, and T. Shimamoto. 2008. First characterization and emergence of SHV-60 in raw milk of a healthy cow in Japan. J. Vet. Med. Sci. 70:1269-1272.

Haran, K. P., S. M. Godden, D. Boxrud, S. Jawahir, J. B. Bender, and S. Sreevatsan. 2012. Prevalence and characterization of Staphylococcus aureus, including methicillin-resistant Staphylococcus aureus, isolated from bulk tank milk from Minnesota dairy farms. J. Clin. Microbiol. 50:688-695.

Hawkey, P. M. 2008. Molecular epidemiology of clinically significant antibiotic resistance genes. Br. J. Pharmacol. 153:S406-S413.

Herrero, M., C. Simo, V. Garcia-Canas, E. Ibanez, and A. Cifuentes. 2012. Foodomics: MS-based strategies in modern food science and nutrition. Mass Spectrom. Rev. 31:49-69.

Hocquette, J. F., H. Boudra, I. Cassar-Malek, C. Leroux, B. Picard, I. Savary-Auzeloux, L. Bernard, A. Cornu, D. Durand, A. Ferlay, D. Gruffat, D. P. Morgavi, and C. Terlouw. 2009. Perspectives offered by "omics" approaches to sustainable herbivore production. Prod. Anim. 22:385-395.

Hoelzer, K., Y. Soyer, L. D. Rodriguez-Rivera, K. J. Cummings, P. L. McDonough, D. J. Schoonmaker-Bopp, T. P. Root, N. B. Dumas, L. D. Warnick, Y. T. Groehn, M. Wiedmann, K. N. K. Baker, T. E. Besser, D. D. Hancock, and M. A. Davis. 2010. The prevalence of multidrug resistance is higher among bovine than human Salmonella enterica serotype Newport, Typhimurium, and 4,5,12:i:isolates in the United States but differs by serotype and geographic region. Appl. Environ. Microbiol. 76:5947-5959.

Huck, J. R., B. H. Hammond, S. C. Murphy, N. H. Woodcock, and K. J. Boor. 2007. Tracking spore-forming bacterial contaminants in fluid milk-processing systems. J. Dairy Sci. 90:4872-4883.

Hwang, C. C., F. Q. Ling, G. L. Andersen, M. W. LeChevallier, and W. T. Liu. 2012. Evaluation of methods for the extraction of DNA from drinking water distribution system biofilms. Microbes Environ. 27:9-18.

Iijima, Y., and K. Aoki. 2009. Application of metabolomics to improve tomato fruit productivity and quality. Engei Gakkai Zasshi $78: 14-22$
Jung, J. Y., S. H. Lee, J. M. Kim, M. S. Park, J.-W. Bae, Y. Hahn, E. L. Madsen, and C. O. Jeon. 2011. Metagenomic analysis of kimchi, a traditional Korean fermented food. Appl. Environ. Microbiol. $77: 2264-2274$.

Kallus, S. J., and L. J. Brandt. 2012. The intestinal microbiota and obesity. J. Clin. Gastroenterol. 46:16-24.

Kotlar, H. K., A. Lewin, J. Johansen, M. Throne-Holst, T. Haverkamp, S. Markussen, A. Winnberg, P. Ringrose, T. Aakvik, E. Ryeng, K. Jakobsen, F. Drablos, and S. Valla. 2011. High coverage sequencing of DNA from microorganisms living in an oil reservoir 2.5 kilometres subsurface. Environ. Microbiol. Rep. 3:674-681.

Kunin, V., A. Copeland, A. Lapidus, K. Mavromatis, and P. Hugenholtz. 2008a. A bioinformatician's guide to metagenomics. Microbiol. Mol. Biol. Rev. 72:557-578.

Kunin, V., J. Raes, J. K. Harris, J. R. Spear, J. J. Walker, N. Ivanova, C. von Mering, B. M. Bebout, N. R. Pace, P. Bork, and P. Hugenholtz. 2008b. Millimeter-scale genetic gradients and communitylevel molecular convergence in a hypersaline microbial mat. Mol. Syst. Biol. 4:198.

Lai, B., R. Ding, Y. Li, L. Duan, and H. Zhu. 2012. A de novo metagenomic assembly program for shotgun DNA reads. Bioinformatics 28:1455-1462.

Lampe, J. W. 2011. Dairy products and cancer. J. Am. Coll. Nutr. 30:464S-470S

Lander, E. S., L. M. Linton, B. Birren, C. Nusbaum, M. C. Zody, J. Baldwin, et al., International Human Genome Sequencing Consortium. 2001. Initial sequencing and analysis of the human genome. Nature 409:860-921.

Liu, W. J., Z. H. Sun, Y. B. Zhang, C. L. Zhang, Menghebilige, M. Yang, T. S. Sun, Q. H. Bao, W. Chen, and H. P. Zhang. 2012. A survey of the bacterial composition of kurut from Tibet using a culture-independent approach. J. Dairy Sci. 95:1064-1072.

Lopez, F. E., M. L. Mercedes Pescaretti, R. Morero, and M. A. Delgado. 2012. Salmonella Typhimurium general virulence factors: A battle of David against Goliath? Food Res. Int. 45:842-851.

Malik, A. C., and A. M. Swanson. 1975. Action of heat-stable Pseudomonas fluorescens protease on sterilized skim milk. J. Dairy Sci. 58:795.

Marchand, S., K. Heylen, W. Messens, K. Coudijzer, P. De Vos, K. Dewettinck, L. Herman, J. De Block, and M. Heyndrickx. 2009. Seasonal influence on heat-resistant proteolytic capacity of Pseudomonas lundensis and Pseudomonas fragi, predominant milk spoilers isolated from Belgian raw milk samples. Environ. Microbiol. 11:467-482.

Marth, E. H., and J. L. Steele. 2001. Applied Dairy Microbiology. 2nd ed. Marcel Dekker Inc., New York, NY.

Martin, N. H., M. L. Ranieri, S. C. Murphy, R. D. Ralyea, M. Wiedmann, and K. J. Boor. 2011. Results from raw milk microbiological tests do not predict the shelf-life performance of commercially pasteurized fluid milk. J. Dairy Sci. 94:1211-1222.

McDougald, D., S. A. Rice, D. Weichart, and S. Kjelleberg. 1998. Nonculturability: Adaptation or debilitation? FEMS Microbiol. Ecol. 25:1-9.

Metzker, M. L. 2010. Applications of next-generation sequencing: Sequencing technologies-The next generation. Nat. Rev. Genet. 11:31-46.

Mills, S., C. Griffin, A. Coffey, W. C. Meijer, B. Hafkamp, and R. P. Ross. 2010. CRISPR analysis of bacteriophage-insensitive mutants (BIMs) of industrial Streptococcus thermophilus - Implications for starter design. J. Appl. Microbiol. 108:945-955.

Morton, D. J., and E. L. Barrett. 1982. Gram-negative respratory bacteria which cause ropy milk constitute a distinct cluster within the genus Acinetobacter. Curr. Microbiol. 7:107-112.

Murphy, S. C. 2010. The preliminary incubation count for raw milkAn old test revisited. Dairy Foods Science Notes, Milk Quality Improvement Program, Cornell University, Ithaca, NY.

Nielsen, S. S. 2002. Plasmin system and microbial proteases in milk: Characteristics, roles, and relationship. J. Agric. Food Chem. 50:6628-6634. 
Noguchi, H., J. Park, and T. Takagi. 2006. MetaGene: Prokaryotic gene finding from environmental genome shotgun sequences. Nucleic Acids Res. 34:5623-5630.

Pagani, I., K. Liolios, J. Jansson, I. M. A. Chen, T. Smirnova, B. Nosrat, V. M. Markowitz, and N. C. Kyrpides. 2012. The Genomes OnLine Database (GOLD) v.4: Status of genomic and metagenomic projects and their associated metadata. Nucleic Acids Res. 40:D571-D579.

Park, Y. K., H. C. Koo, S. H. Kim, S. Y. Hwang, W. K. Jung, J. M. Kim, S. Shin, R. T. Kim, and Y. H. Park. 2007. The analysis of milk components and pathogenic bacteria isolated from bovine raw milk in Korea. J. Dairy Sci. 90:5405-5414.

Pickard, D., J. Wain, S. Baker, A. Line, S. Chohan, M. Fookes, A. Barron, P. Gaora, J. Chabalgoity, N. Thanky, C. Scholes, N. Thomson, M. Quail, J. Parkhill, and G. Dougan. 2003. Composition, acquisition, and distribution of the Vi exopolysaccharide-encoding Salmonella enterica pathogenicity island SPI-7. J. Bacteriol. 185:5055-5065.

Pitkälä, A., M. Haveri, S. Pyorälä, V. Myllys, and T. Honkanen-Buzalski. 2004. Bovine mastitis in Finland 2001-Prevalence, distribution of bacteria, and antimicrobial resistance. J. Dairy Sci. $87: 2433-2441$

Rho, M. N., H. X. Tang, and Y. Z. Ye. 2010. FragGeneScan: Predicting genes in short and error-prone reads. Nucleic Acids Res. 38:e191.

Rohrmann, J., T. Tohge, R. Alba, S. Osorio, C. Caldana, R. McQuinn, S. Arvidsson, M. J. van der Merwe, D. M. Riano-Pachon, B. Mueller-Roeber, Z. J. Fei, A. N. Nesi, J. J. Giovannoni, and A. R. Fernie. 2011. Combined transcription factor profiling, microarray analysis and metabolite profiling reveals the transcriptional control of metabolic shifts occurring during tomato fruit development. Plant J. 68:999-1013.

Santos, T. M. A., R. O. Gilbert, and R. C. Bicalho. 2011. Metagenomic analysis of the uterine bacterial microbiota in healthy and metritic postpartum dairy cows. J. Dairy Sci. 94:291-302.

Schmeisser, C., C. Stockigt, C. Raasch, J. Wingender, K. N. Timmis, D. F. Wenderoth, H. C. Flemming, H. Liesegang, R. A. Schmitz, K. E. Jaeger, and W. R. Streit. 2003. Metagenome survey of biofilms in drinking-water networks. Appl. Environ. Microbiol. 69:7298-7309

Sela, D. A., D. Garrido, L. Lerno, W. Shuai, K. Tan, E. Hyun-Ju, A Joachimiak, C. B. Lebrilla, and D. A. Mills. 2012. Bifidobacterium longum ssp. infantis ATCC 15697 alpha-fucosidases are active on fucosylated human milk oligosaccharides. Appl. Environ. Microbiol. 78:795-803.

Shelley, A. W., H. C. Deeth, and I. C. Macrae. 1986. Growth of lipolytic psychrotrophic pseudomonads in raw and ultra-heat-treated milk. J. Appl. Bacteriol. 61:395-400.

Shendure, J., and H. L. Ji. 2008. Next-generation DNA sequencing. Nat. Biotechnol. 26:1135-1145.

Straley, B. A., S. C. Donaldson, N. V. Hedge, A. A. Sawant, V. Srinivasan, S. P. Oliver, and B. M. Jayarao. 2006. Public health significance of antimicrobial-resistant gram-negative bacteria in raw bulk tank milk. Foodborne Pathog. Dis. 3:222-233.

Taponen, S., L. Salmikivi, H. Simojoki, M. T. Koskinen, and S. Pyorala. 2009. Real-time polymerase chain reaction-based identification of bacteria in milk samples from bovine clinical mastitis with no growth in conventional culturing. J. Dairy Sci. 92:2610-2617.

Ternström, A., A. M. Lindberg, and G. Molin. 1993. Classification of the spoilage flora of raw and pasteurized bovine milk, with special reference to Pseudomonas and Bacillus. J. Appl. Bacteriol. $75: 25-34$
Thomas, T., J. Gilbert, and F. Meyer. 2012. Metagenomics-A guide from sampling to data analysis. Microb. Inform. Exp. 2:3.

Tomasula, P. M., S. Mukhopadhyay, N. Datta, A. Porto-Fett, J. E. Call, J. B. Luchansky, J. Renye, and M. Tunick. 2011. Pilot-scale crossflow-microfiltration and pasteurization to remove spores of Bacillus anthracis (Sterne) from milk. J. Dairy Sci. 94:4277-4291.

Tringe, S. G., C. von Mering, A. Kobayashi, A. A. Salamov, K. Chen, H. W. Chang, M. Podar, J. M. Short, E. J. Mathur, J. C. Detter, P. Bork, P. Hugenholtz, and E. M. Rubin. 2005. Comparative metagenomics of microbial communities. Science 308:554-557.

Tuohy, K. M., C. Gougoulias, Q. Shen, G. Walton, F. Fava, and P. Ramnani. 2009. Studying the human gut microbiota in the transomics era-Focus on metagenomics and metabonomics. Curr. Pharm. Des. 15:1415-1427.

Turnbaugh, P. J., R. E. Ley, M. A. Mahowald, V. Magrini, E. R. Mardis, and J. I. Gordon. 2006. An obesity-associated gut microbiome with increased capacity for energy harvest. Nature 444:1027-1031.

Venter, J. C., M. D. Adams, E. W. Myers, P. W. Li, R. J. Mural, G. G. Sutton, et al. 2001. The sequence of the human genome. Science 291:1304-1351.

Venter, J. C., K. Remington, J. F. Heidelberg, A. L. Halpern, D. Rusch, and J. A. Eisen. 2004. Environmental genome shotgun sequencing of the Sargasso Sea. Science 304:66-74.

Vogel, R. F., M. Pavlovic, M. A. Ehrmann, A. Wiezer, H. Liesegang, S. Offschanka, S. Voget, A. Angelov, G. Boecker, and W. Liebl. 2011. Genomic analysis reveals Lactobacillus sanfranciscensis as stable element in traditional sourdoughs. Microb. Cell Fact. 10(Suppl. 1):S6

Walther, C., A. Rossano, A. Thomann, and V. Perreten. 2008. Antibiotic resistance in Lactococcus species from bovine milk: Presence of a mutated multidrug transporter $m d t(\mathrm{~A})$ gene in susceptible Lactococcus garvieae strains. Vet. Microbiol. 131:348-357.

Warnecke, F., P. Luginbuehl, N. Ivanova, M. Ghassemian, T. H Richardson, J. T. Stege, et al. 2007. Metagenomic and functional analysis of hindgut microbiota of a wood-feeding higher termite. Nature 450:560-565

Weckx, S., J. Allemeersch, R. Van der Meulen, G. Vrancken, G. Huys, P. Vandamme, P. Van Hummelen, and L. De Vuyst. 2011. Metatranscriptome analysis for insight into whole-ecosystem gene expression during spontaneous wheat and spelt sourdough fermentations. Appl. Environ. Microbiol. 77:618-626.

Wehr, H. M., and J. F. Frank. 2004. Standard Methods for the Examination of Dairy Products. 17th ed. American Public Health Association, Baltimore, MD.

White, C. H., W. T. Gillis, D. L. Simmler, M. K. Galal, J. R. Walsh, and J. T. Adams. 1978. Evaluation of raw milk quality tests. J. Food Prot. 41:353-360.

Wooley, J. C., A. Godzik, and I. Friedberg. 2010. A primer on metagenomics. PLoS Comput. Biol. 6:e1000667.

Yeung, P. S. M., C. L. Kitts, R. Cano, P. S. Tong, and M. E. Sanders. 2004. Application of genotypic and phenotypic analyses to commercial probiotic strain identity and relatedness. J. Appl. Microbiol. 97:1095-1104.

Yooseph, S., W. Li, and G. Sutton. 2008. Gene identification and protein classification in microbial metagenomic sequence data via incremental clustering. BMC Bioinformatics 9:182.

Yooseph, S., G. Sutton, D. B. Rusch, A. L. Halpern, S. J. Williamson, K. Remington, et al. 2007. The Sorcerer II global ocean sampling expedition: Expanding the universe of protein families. PLoS Biol. 5:e16. http://dx.doi.org/10.1371/journal.pbio.0050016. 